\title{
Topological descriptors of philosophical text
}

\author{
Marina Danilova ${ }^{1}$, Anatoliy Enikeev ${ }^{1, *}$ \\ ${ }^{1}$ Kuban State Agrarian University, 350044 Krasnodar, Russia
}

\begin{abstract}
The article considers the problem of topological descriptors of a philosophical text. Topological descriptors act as discursive points for the localization of the philosophical text, which allow us to describe its role and place in the production of modern humanitarian knowledge. Three perspectives of the analysis of the philosophical text in the contemporary sociocultural situation are outlined: the perspective of historical and philosophical research, the perspective of cultural research and the perspective of modern humanitarian knowledge. The historical and philosophical perspective from the point of view of topology is described through genre differences between philosophical texts, and also taking into account the differences between philosophical schools, trends, styles of thinking in intellectual history. The perspective of cultural research includes a philosophical text in a wide context of political, social and cultural transformations of modern society, and it becomes possible to talk about social topology. The perspective of modern humanitarian knowledge is analyzed from the perspective of the rehabilitation of philosophical discourse, the need for detailed textual work for the full inclusion of philosophy in the production process of significant social and cultural knowledge. As an original methodological approach, the article describes topological analytics, which is actively used by modern researchers to solve a whole range of issues of localization, description and understanding of the role of a philosophical text in modern humanities. Conclusions are drawn about the prospects of further research in this direction.
\end{abstract}

\section{Introduction (description of the problem situation)}

The situation in modern humanities associated with determining the status of philosophical discourse and the positioning of philosophical texts requires a number of significant clarifications. The vulnerability of philosophical discourse on the part of existing power institutions is largely determined by the legacy of the post-Soviet humanitarian trend with its attempts to "get out of the crisis" (Stepin \& Kasavin 2014), as well as by an inadequate assessment of the methodology of postmodern studies in the field of text (Enikeev 2014). The problem of positioning philosophical texts is predetermined, on the one hand, by the need to use the Anglo-Saxon (analytical) tradition of working with text as opposed to the continental tradition (Hintikka 2011; Rorty 2018), and on the other hand, the weak inclusion of philosophical discourse in modern cultural and social processes, the

\footnotetext{
*Corresponding author: rizoma69@yandex.ru
} 
philosophical text is still too often "marginalized" (Girenok 2016, p.22). Some attempts by domestic researchers to determine the status of philosophical discourse in modern humanities are associated either with the need to ensure personal freedom in public space (Mezhuev 2012), or with "philosophical expertise" (Pronin, Yudin \& Sineokaya 2017), or with thinking over the status of a philosophical text as a comment (Mayatsky 2015). In this regard, the urgent problem is the redefinition of the role and status of the philosophical text in the space of modern humanitarian practices, taking into account the nature of modern discussions.

\section{Statement of the problem and the degree of its development}

In determining the contemporary philosophical discourse in general and the specifics of the philosophical text in particular, one should take into account those "epistemological obstacles" (the term of G. Bashlyar), which over time inevitably accumulate in science. They should be understood as "... the burden of tradition, which impedes adequate scientific analysis and generates expectations that cannot be realized ..." (Kurennoy 2004, p.4). In relation to Russian philosophy, these expectations are largely associated with the weakening of its "epistemological claims", which in turn is "... a predictable consequence of the lack of systematic philosophical positions that can consolidate any significant part of the professional community of philosophers ..." (Kurennoy 2004, p.14)

In this regard, the opinion of V. Kurennoy, who argues that “... it is necessary to proceed from the fact that philosophy is not a priori guaranteed, is guaranteed either in the scientific community or in culture. Ultimately, the philosophical view of the world can be replaced by a religious or by a system of views, which is one of the varieties of scientified reductionism, developed with a practically value bias..." (Kurennoy 2004, p.18). While epistemological obstacles as a "burden of tradition" concern the whole of European philosophy, the specifics of the domestic philosophical discourse are largely determined by the complexity of the sociocultural and institutional situation that Russian science as a whole and philosophy in particular have been forced to face. At the same time, one should take into account that "scientified reductionism" (the term of V. Kurennoy), which philosophical discourse has to be fought against, justifying its right to self-identification.

A variant of such self-identification may be textual work within the domestic philosophical tradition, which will ensure the prestige of philosophy in modern humanitarian culture. One can agree with the opinion of V. Kurennoy that despite notable efforts in this direction, on the whole, it should be recognized that "... with respect to philosophy, one can state a noticeable neglect of textual work ...” (Kurennoy 2004, p.23). However, in the last decade, domestic researchers are trying to fill this gap. This work is carried out both in the context of historical and philosophical research (Vizgin 2013; Ryskeldieva 2015, 2017), and in solving methodological issues of publishing texts (Methodological problems 2016). Of particular note is the problem of translating philosophical texts, which is also actively discussed in modern philosophical literature (Smirnov 2012; Alekseeva 2016). A completely unique phenomenon in Russian philosophical thought is the project "Anatomy of Philosophy: How the Text Works" led by Yu. Sineokoi (Sineokaya 2016; Discussion of the 2017 project).

\section{The purpose and objectives of the study}

The purpose of the present study is the substantiation of topological descriptors of a philosophical text that will help localize philosophical discourse and outline the main strategies for its interaction with other institutions. As research objectives, we should 
propose the idea that a philosophical text should find its topological localization in the three most resonant aspects: (1) in relation to philosophical tradition (historical and philosophical perspective), (2) in relation to modern culture (cultural studies) and (3) in relation to the humanities (the perspective of modern humanities).

\section{Research methodology}

The solution to the problem of positioning philosophical texts in the space of modern humanitarian discourse is possible using topological analytics methods. The topological analytics of the philosophical text is represented by a number of independent research projects in the field of the methodology of humanitarian knowledge. The first in the domestic philosophical tradition of a convincing example of the use of topological analytics methods can be considered a course of lectures on Proust M. Mamardashvili (Mamardashvili 2016). Another successful experience in the development of topological analytics methods for studying philosophical discourse can be considered the project of "landscape metaphysics" by V. Podoroga (Podoroga 2013), in which he convincingly shows the variety of communicative strategies for positioning a philosophical text in the modern sociocultural situation. Of the modern analysts using a topological methodology, it is worth mentioning, first of all, S. Azarenko (Azarenko 2000, 2012, 2016), expanding this issue to an analysis of culture and society. The project of "topological reflection" by V. Savchuk (Savchuk 2012) has a certain value, in which he substantiates the need to move away from the classical "optical reflection" in determining the role and status of the philosophical discourse of our time. A. Gryakalov (Gryakalov 2019), who uses a topological methodology to analyze aesthetic experience and subjective strategies for the realization of personality, can also be added to these authors. In general, it should be said that the methodology of topological analytics has become widespread in modern humanities, largely determining the specifics of studies of a philosophical text (Enikeev 2014).

\section{Research questions (cases and their analysis)}

The problem of topological descriptors of a philosophical text can be considered in terms of three main areas of localization of philosophical discourse: (1) in relation to philosophical tradition (historical and philosophical perspective), (2) in relation to modern culture (perspective of cultural research) and (3) in attitude to the humanities (perspective of modern humanities).

(1) In relation to the philosophical tradition, the problem of topological ways of organizing the space of a text can be solved in several ways. The first method is demonstrated by R. Rorty by highlighting the four main genres of historical and philosophical research (Rorty 2017). His method of intellectual history, which overcomes the shortcomings of both rational and historical reconstruction, and the Geistesgeschichte, justifies itself taking into account current trends in the study of a philosophical text (Plotnikov 2001; Khlebnikova 2013). The second way can be considered the work of Russian historians of philosophy who propose to "read" philosophical texts (Bibikhin 2009), restoring the ancient context of thinking (Vasilieva 2008; Mayatsky 2015), or rethinking the current state of historical and philosophical research (Kurennoy 2004; Vizgin 2013). One way or another, one should always take into account the historical and philosophical context when describing the contribution of a text to a philosophical tradition. The descriptors of this localization will be the lines of force that permeate the philosophical tradition, they can be connected with the division into philosophical schools, commenting 
practices, genre differences between texts, any attempts to write a coherent intellectual history of philosophical discourse.

(2) From the perspective of cultural research and in relation to modern culture, philosophical discourse is also positioned in various ways. Variant V. Savchuk connects the topology of the philosophical text with reflexivity as such, understood not so much as a non-classical counterweight to the classical "optical reflection", but as a combination of bodily practices with their psychomotor skills and tactile experience of understanding (Savchuk 2012). S. Azarenko (Azarenko 2000) also speaks of bodily experience in its social context, the social topology he develops not only enriches the discourse of modern cultural research, but also is an independent paradigm of topological analytics. Azarenko's variant is close to the project of A. Gryakalov, which also proceeds from the importance of subjective experience, but extrapolates it to the field of aesthetics, describing the topographic constants of the cultural reproduction of subjectivity (Gryakalov 2019). It is the cultural context that allows us to answer the question "what is philosophy" again. In this connection, one can agree with the opinion of V. Podorogi, who states: "The answer to the question: what is philosophy? - lies outside the plane of philosophy itself or philosophizing. This question can be located on different horizons of waiting for an answer: historical (era); historiographical (event); genealogical (origin and place); disciplinary (institute); affective (passion); and, finally, metaphysical (interrogation as a principle)" (Podoroga 2009, p.5). Variant V. Podorogi is most convincing because it fits philosophical discourse into the contemporary cultural context, topologically outlining possible descriptors, and also pointing out the importance of the political factor in understanding cultural research (Kurennoy 2012).

(3) In relation to the humanities, the philosophical discourse in general and the philosophical text in particular also solve a number of topological problems of their own description. Firstly, this is the problem of translating philosophical texts (Smirnov 2012; Alekseeva 2016), it is the translation that allows you to enter a philosophical text not only into the previous tradition, but also into the space of modern humanitarian discourse. This is doubly important for Russian translations, since there is a problem of national identification of philosophical discourse associated with the development of European intellectual space by Russian philosophers. Secondly, this is the interdisciplinary problem inherent in modern humanitarian research (Danilova \& Sukhoverkhov 2016). The philosophical text is forced to either position itself within the rigid framework of scientific discourse, developing textual strategies inherent in the American analytical tradition (Hintikka 2011; Blokhina 2015; Rorty 2018), or to remain part of a metaphysical project to generate unique meanings inherent in the domestic tradition (Bibikhin 2009; Azarenko 2012) . Thirdly, this is the textual work of modern analysts, focusing on the specifics of a philosophical text. The description of the text becomes possible either through the argumentation system (Alekseev 2006), or by justifying it in the context of the history of previous philosophy (Ryskeldieva 2015, 2017; Enikeev 2018), or as the laborious work of "anatomizing" the philosophical text (Sineokaya 2016; Discussion of the 2017 project).

\section{Conclusion (conclusions and prospects)}

The problem of topological descriptors of a philosophical text remains an urgent area of research for modern analysts. Relevance is largely determined by the need for cultural and social localization of philosophical discourse in modern communication processes. Prospects for further research in this direction may be associated with the development of three conceptual approaches to understanding the role and function of a philosophical text in culture. Firstly, this is a textual work on the translation, analysis, commenting on the philosophical heritage, which will save the most significant examples of philosophical 
discourse. Secondly, this is work to expand the context of the use of philosophical discourse in social, cultural, political and other studies, philosophy should regain its lost status and prestige in the public mind. And thirdly, the topological descriptors of the philosophical text are necessary for the further development of the interdisciplinary connections of philosophy with other humanities and social sciences. It seems that it is a philosophical text, with its topological component, that should provide meaningful communication with a wide range of modern cultural practices, thereby developing the traditions of philosophizing in the future.

\section{References}

1. S.A. Azarenko, The topology of cultural reproduction (Publishing House of the Ural State University, Yekaterinburg, 2000).

2. S.A. Azarenko, Russian philosophizing and topological philosophy in modern times, News of the Ural Federal University. Ser. 3, Social Sciences, 2 (103), 160-170 (2012).

3. S.A. Azarenko, Topological philosophizing and social communication, Proceedings of Saratov University. New series. Ser. Philosophy. Psychology. Pedagogy, 16 (4), $412-$ 417 (2016). DOI: 10.18500 / 1819-7671-2016-16-4-412-417.

4. A.P. Alekseev, Philosophical text: ideas, argumentation, images (Progress Tradition, Moscow, 2006).

5. M.L. Alekseeva, The problem of untranslability in philosophical studies of the beginning of the XXI century, Voprosy Filosofii, 3, 51-60 (2016).

6. V.V. Bibikhin, Reading philosophy (Science, St. Petersburg, 2009).

7. N.A. Blokhina, The paradox of analysis and the paradox of analytical philosophy, Voprosy Filosofii, 3, 186-196 (2015).

8. T.V. Vasilieva, The poetics of ancient philosophy (Academic project, Moscow, 2008).

9. V.P. Vizgin, Toward an Update on the History of Philosophy: Thinking ad hoc, Philosophical Journal, 2 (11), 70-82 (2013).

10. F.I. Girenok, Clip consciousness (Prospect, Moscow, 2016).

11. A.A. Gryakalov, Topos and subjectivity. Evidence of approval (Science, St. Petersburg, 2019).

12. M.I. Danilova, A.V. Sukhoverkhov, Biological and social foundations of the evolution of language and communication: modern discussions, Voprosy Filosofii, 12, 77-87 (2015).

13. A.A. Enikeev, The methodology of topological analytics in the socio-humanitarian discourse of the twentieth century (historical excursus and problem statement), Cultural life of the South of Russia, 3 (54), 34-36 (2014).

14. A.A. Enikeev, J. Deleuze, Stoicism and the birth of philosophical topology. Context in reflection: philosophy about the world and man, 7 (1A), 29-41 (2018).

15. V. Kurennoy, Notes on some problems of modern Russian history of philosophy, Logos, Philosophical and literary magazine, 3-4 (43), 3-29 (2004).

16. V. Kurennoy, Research and political cultural research program, Logos, Philosophical and literary magazine. 1 (85), 14-79 (2012).

17. M.K. Mamardashvili, Full course of lectures. The philosophy of Europe. The psychological topology of the path (AST, Moscow, 2016). 
18. M. Mayatsky, To the archeology of current and future practices of mastering a philosophical text: an antique commentary, Logos. Philosophical and literary magazine. 25 (6) 1-21 (2015).

19. V.M. Mezhuev, Who needs philosophy today and why?, Philosophical Journal T, 2 (9), 5-16 (2012).

20. B.I. Pruzhinin, N.S. Autonomova, T.V. Artemyeva, V.K. Kantor, I.A. Mikhailov, E.V. Pasternak, V.N. Porus, I.S. Razumovsky, L.T. Ryskeldieva, A.V. Smirnov., T.G. Shchedrina, V.V. Yantsen, Methodological problems of publishing philosophical texts, Materials of the conference - "round table", Voprosy Filosofiii, 3, 5-50 (2016).

21. M.F. Bykova, A.A. Guseinov, V.A. Lektersky, N.V. Motroshilova, Yu.V. Sineokaya, A.V. Smirnov, E.Yu. Soloviev, M.T. Stepanyants, Discussion of the project "Anatomy of Philosophy: How the Text Works.", Voprosy Filosofii, 7, 109-146 (2017).

22. V.I. Plotnikov, The variety of genres of philosophical discourse (Bank of cultural information, Yekaterinburg, 2001).

23. V.A. Podoroga, What they ask when they ask, "What is philosophy?", Philosophical Journal, 1 (2), 5-17 (2009).

24. V.A. Podoroga, Metaphysics of the landscape. Communicative strategies in the philosophical culture of the XIX-XX centuries (Canon +, Moscow, 2013).

25. M.A Pronin, B.G. Yudin, Yu.V. Sineokaya, Philosophy as an examination, Philosophical Journal, 10 (2), 79-96 (2017).

26. R. Rorty, Historiography of Philosophy: Four Genres (Canon +, Moscow, 2017).

27. R. Rorty, Analytical and transformative philosophy, Philosophical Journal, 11 (3), 5-19 (2018).

28. L.T. Ryskeldieva, About philosophical textology, or What history of philosophy can teach, Voprosy Filosofii, 1, 106-114 (2015).

29. L.T. Ryskeldieva, Text culture as an object of historical and philosophical research, Philosophical Journal, 10 (1), 136-153 (2017).

30. V.V. Savchuk, Topological reflection (Canon +, Moscow, 2012).

31. Yu.V. Sineokaya, Anatomy of philosophy: how the text works (Yask Publishing House, Moscow, 2016).

32. A.V. Smirnov, Philosophy of translation and translation of philosophy, Philosophical Journal, 1 (8), 40-58 (2012).

33. V.S. Stepin, I.T. Kasavin, Philosophical discourse: ten years later, Epistemology \& Philosophy of Science, T.XLI, 3, 18-52 (2014).

34. Y. Hintikka, Philosophical studies: problems and prospects, Voprosy Filosofii, 7, 3-17 (2011).

35. O.V. Khlebnikova, Classification of genres of philosophical literature, Bulletin of the Kemerovo State University, 4 (56) T. 1, 201-207 (2013). DOI: 10.21603 / 2078-89752013-4-201-207. 